\title{
Strategy for Treating a Landfill Leachate by Integration of Physico-Chemical and Photo-Fenton Processes
}

\author{
Valdislaine M. Silva, Oswaldo Gomes Júnior, Jader O. Silva, Arlene B. S. Nossol, \\ Raquel M. F. Sousa, Antonio E. H. Machado and Alam G. Trovó*
}

Instituto de Química, Universidade Federal de Uberlândia, 38400-902 Uberlândia-MG, Brazil

\begin{abstract}
This study reports a protocol for the treatment of a sanitary landfill leachate through integration between a stage of coagulation-flocculation, a step of filtration of the resulting suspension, and application of the photo-Fenton process using a ferrioxalate complex and solar irradiation. The best results for turbidity removal by coagulation-flocculation were reached using $\mathrm{Al}^{3+}$ as nitrate salt mainly using concentrations up close $4.4 \mathrm{mmol} \mathrm{L}^{-1}$, at the natural $\mathrm{pH}$ of the effluent ( $\mathrm{pH} 7.9$ ), when the removal of $66 \%$ of the turbidity was achieved. By using a ferrioxalate complex after adjusting the $\mathrm{pH}$ of the effluent to 5 , it was possible to circumvent the classical limitations of the Fenton process (related to the $\mathrm{pH}$ of the medium limited to between 2.5 and 3.0), performing a removal of $68 \%$ of the remaining dissolved organic carbon. The global dissolved organic carbon removal in this process was of $86 \%$ after a membrane filtration step before the photo-Fenton process.
\end{abstract}

Keywords: GC-FID, decontamination, integration of processes, iron-complex, mineralization, modified photo-Fenton

\section{Introduction}

Landfilling of solid wastes produces leachate which may contaminate nearby groundwater or surface water if not properly treated. Leachate is characterized by high levels of chemical and biochemical oxygen demands (COD and $\mathrm{BOD}_{5}$ ) for landfills with less than two years, and low biodegradability for mature landfills with more than ten years. ${ }^{1,2}$

These effluents are characterized by a dark color and presence of large amounts of suspended solids, ammonia, inorganic ions (chloride, sulfate, etc.), metals and other toxic components. In view of this, they tend to present acute and chronic toxicities, ${ }^{3-5}$ compromising the efficiency of biological processes, especially in the case of mature effluents. ${ }^{2}$ Considering the complexity of such effluents, the coupling of different technologies can be a good alternative for treatment. ${ }^{6-8}$

A previous study ${ }^{7}$ has demonstrated that the composition of sanitary landfill leachate does not compromise the efficiency of mineralization by photo-Fenton process, although influences significantly the treatment time and the consumption of $\mathrm{H}_{2} \mathrm{O}_{2}$. It has been reported a significant

*e-mail: alamtrovo@ufu.br reduction in the treatment time and amount of $\mathrm{H}_{2} \mathrm{O}_{2}$ added, when the treatment via photo-Fenton reactions is preceded by a pre-treatment via coagulation-flocculation. ${ }^{7}$ On the other hand, it is known that the classic Fenton process is limited to a narrow range of $\mathrm{pH}^{.9-11}$ This limits the applicability of Fenton reactions in the treatment of real effluents, even when combined with a biological process, since steps of acidification and neutralization add costs to the overall process, in addition to contributing to the reduction of the treated water quality due to the high concentration of salts. ${ }^{12,13}$ This has encouraged the research of alternatives with lower operating costs for obtaining similar or better results using other $\mathrm{pH}$ ranges. Many of these studies have focused in the use of iron complexes. ${ }^{14-16}$ Good degradation efficiencies have been reported using iron complexes ${ }^{10}$ when compared with the use of the classic photo-Fenton process. ${ }^{17-20}$ One of the advantages of some of these complexes, such as oxalate and citrate,,$^{17,18,21}$ lies in the ability to absorb radiation, particularly in the visible, with expressive quantum yields. . $^{18,22}$

However, in some situations, the advantage of using iron complexes is limited by the fact that certain target compounds form stable complexes with iron, which however are less active from the photocatalytic point of view. ${ }^{10,18,21}$ Worth mentioning that during the classic 
photo-Fenton process, humic and fulvic acids, naturally present in the landfill leachate, tend to precipitate dissolved iron or form stable iron complexes, ${ }^{23,24}$ compromising the photocatalytic process.

Although several studies have been published reporting alternatives for the treatment of sanitary landfill leachate, $, 725,26$ to the best of our knowledge, there are no studies published reporting the treatment of this kind of effluent by photo-Fenton process using iron complexes, in $\mathrm{pH}$ near neutrality.

In a previous work, ${ }^{7}$ we studied the influence of the composition of sanitary landfill leachate on the removal of dissolved organic carbon (DOC) by photo-Fenton process, pointing out the need of a previous treatment combining coagulation-flocculation, and decantation, to ensure an efficient DOC removal in a later classic photo-Fenton process. In this study, we applied a similar procedure, including the filtration of the supernatant in the pretreatment and the use of iron complexes in the photo-Fenton process. We also defined, among the possible combinations between $\mathrm{Al}^{3+}$ and $\mathrm{Fe}^{3+}$ and three different anions $\left(\mathrm{Cl}^{-}, \mathrm{NO}_{3}{ }^{-}\right.$and $\left.\mathrm{SO}_{4}{ }^{2-}\right)$ the most effective coagulant agent and its concentration for the flocculation of the suspended solids. The supernatant obtained in this step was treated by solar photocatalysis, when the efficiency of mineralization of two $\mathrm{Fe}^{3+}$ sources (citrate and oxalate) in two different $\mathrm{pH}$ was evaluated. The better conditions were applied to the supernatant after membrane filtration. Thus, a protocol for treatment of a sanitary landfill leachate combining a sequence of physicochemical (coagulation-flocculation-decantation, followed by $\mathrm{pH}$ adjustment to 5 and filtration) and photocatalytic (photo-Fenton) processes was proposed.

\section{Experimental}

\section{Reagents}

All solutions, except the landfill leachate, were prepared with distilled water.

$\mathrm{FeCl}_{3} \cdot 6 \mathrm{H}_{2} \mathrm{O}$ (F. Marques de Sá), $\mathrm{Fe}\left(\mathrm{NO}_{3}\right)_{3} \cdot 9 \mathrm{H}_{2} \mathrm{O}$ (Synth), $\mathrm{Fe}_{2}\left(\mathrm{SO}_{4}\right)_{3}$ (Reagen), $\mathrm{AlCl}_{3} \cdot 6 \mathrm{H}_{2} \mathrm{O}$ (Synth), $\mathrm{Al}\left(\mathrm{NO}_{3}\right)_{3} \cdot 9 \mathrm{H}_{2} \mathrm{O}$ (Vetec) and $\mathrm{Al}_{2}\left(\mathrm{SO}_{4}\right)_{3} \cdot 18 \mathrm{H}_{2} \mathrm{O}$ (Reagen) were used in the coagulation-flocculation-decantation tests. Ammonium and $\mathrm{Fe}^{3+}$ citrate $\left(\mathrm{C}_{6} \mathrm{H}_{11} \mathrm{FeNO}_{7}\right)$ (Vetec)-FeCit and potassium ferrioxalate $\left(\mathrm{K}_{3} \mathrm{Fe}\left(\mathrm{C}_{2} \mathrm{O}_{4}\right)_{3} \cdot 3 \mathrm{H}_{2} \mathrm{O}\right)$ - $\mathrm{FeOx}$ were used as iron sources during the photo-Fenton experiments. The $\mathrm{FeOx}$ was prepared and purified as described by literature. ${ }^{27} \mathrm{H}_{2} \mathrm{O}_{2}$ $(30 \% \mathrm{~m} / \mathrm{m}), \mathrm{NH}_{4} \mathrm{VO}_{3}, \mathrm{Na}_{2} \mathrm{SO}_{3}$, all from Vetec, were used as received. Aqueous solutions of $\mathrm{H}_{2} \mathrm{SO}_{4}$ and $\mathrm{NaOH}$ (Vetec) were used for $\mathrm{pH}$ adjustments.

\section{Sampling of the sanitary landfill leachate}

The leachate under study was collected in a municipal landfill located in Uberlândia city, Minas Gerais state, Brazil. This landfill is in activity since 2010, receiving approximately 490 ton of household wastes per day. A sample of $50 \mathrm{~L}$ of this leachate was collected directly from a collection box at the exit of the landfill cell, just before entering the sewage treatment plant for municipal effluents. The collected leachate was kept refrigerated at $4{ }^{\circ} \mathrm{C}$ until use. The main chemical-physical characteristics of the collected material were quantified.

Pre-treatment by coagulation, flocculation and decantation

The experiments were performed in the lab at the natural $\mathrm{pH}$ of the landfill leachate $(\mathrm{pH}$ 7.9). The role of the association between two coagulant agents $\left(\mathrm{Al}^{3+}\right.$ and $\left.\mathrm{Fe}^{3+}\right)$ and three anions $\left(\mathrm{Cl}^{-}, \mathrm{NO}_{3}{ }^{-}\right.$and $\left.\mathrm{SO}_{4}{ }^{2-}\right)$ on the flocculation of the suspended material was evaluated monitoring the removal of apparent color and turbidity. ${ }^{7}$ The tests were performed using different concentrations of the coagulant ion (between 2.2 and $17.1 \mathrm{mmol} \mathrm{L}^{-1}$ of $\mathrm{Fe}^{3+}$ or $\mathrm{Al}^{3+}$ ), using beakers containing $50 \mathrm{~mL}$ of the landfill leachate. After the addition of the coagulant, the effluent was maintained under magnetic stirring at $450 \mathrm{rpm}$, which was slowed down to $60 \mathrm{rpm}$ after $5 \mathrm{~min}$. This stirring rate was maintained for $20 \mathrm{~min}$, for flocculation. After this period of time, the suspension was maintained at rest for $60 \mathrm{~min}$, for sedimentation. The supernatant fraction was withdrawn from a point located about $1.5-2.0 \mathrm{~cm}$ below the top of the liquid level and submitted to analyses. ${ }^{7}$

Once the most appropriate coagulant/anion and concentration were defined $\left(4.4 \mathrm{mmol} \mathrm{L}^{-1} \mathrm{Al}^{3+}\right.$, used as $\left.\mathrm{Al}\left(\mathrm{NO}_{3}\right)_{3}\right)$, a total volume of $30 \mathrm{~L}$ of the effluent was treated by this process. In this case, the effluent was kept at rest for $2 \mathrm{~h}$, being the supernatant collected and stored away from light and under refrigeration.

Treatment using the photo-Fenton process under solar irradiation

The solar photocatalysis was performed employing the supernatant obtained in the previous stage, in two different experiments: (i) using the supernatant as collected, studying the role of the source of $\mathrm{Fe}^{3+}\left(2 \mathrm{mmol} \mathrm{L}^{-1}\right.$ of citrate or oxalate of $\mathrm{Fe}^{3+}$, respectively $\mathrm{FeCit}$ or $\mathrm{FeOx}$ ) and of the $\mathrm{pH}$ (7.7 and 5.0) on the organic matter mineralization; (ii) the better conditions found in $(i)$ were applied to the supernatant after filtration in membrane with mean pore size of $0.45 \mu \mathrm{m}$. For this experiment, gas chromatograph equipped with 
a flame ionization detector (GC-FID) analyses were also performed. In all cases, the concentration of $\mathrm{Fe}^{3+}$ used in these experiments was based on a previous study. ${ }^{7}$

The experiments were performed using $800 \mathrm{~mL}$ of the effluent in dark glass square containers with $0.13 \mathrm{~m}$ side and $5.5 \mathrm{~cm}$ deep (irradiated area of $0.016 \mathrm{~m}^{2}$ ), resulting in an optical path of $5.0 \mathrm{~cm}$. The reactions were carried between 9 a.m. and 16 p.m., in a range of temperatures of $33.2 \pm 5.3^{\circ} \mathrm{C}$, during the winter and spring, in the city of Uberlândia, Brazil (185'08's; 48¹6’37'W).

During the reactions, the irradiance was monitored in the UVA (320-400 nm) using a PMA 2100 radiometer (Solar Light Co.) with the sensor placed at the same angle of incidence of radiation in the reactor, being obtained an average irradiance of $25 \pm 8 \mathrm{~W} \mathrm{~m}^{-2}$. Aliquots were collected at a constant value of accumulated dose of UVA radiation. The monitoring of the reaction through the accumulated radiation dose is justified because it facilitates the reproduction of the experiment under any conditions, since the dose is directly related to a same amount of incident photons..$^{20,28,29}$

In all experiments, the concentration of $\mathrm{H}_{2} \mathrm{O}_{2}$ was kept between 200 and $500 \mathrm{mg} \mathrm{L}^{-1}$ by sequential additions of this additive, after $60-80 \%$ of consumption, as indicated by the analyses performed throughout the experiments. This procedure was used to prevent an excess of $\mathrm{H}_{2} \mathrm{O}_{2}$ and consequently, the occurrence of parallel reactions and ineffective, resulting from the addition at once, of a high concentration of this additive. ${ }^{30}$ After sampling and before all analyses, a calculated volume of $1.0 \mathrm{~mol} \mathrm{~L}^{-1}$ of an aqueous solution of $\mathrm{Na}_{2} \mathrm{SO}_{3}$ was added to the samples (except in the analyses of $\mathrm{H}_{2} \mathrm{O}_{2}$ and iron), according to the stoichiometry between $\mathrm{H}_{2} \mathrm{O}_{2}$ and $\mathrm{Na}_{2} \mathrm{SO}_{3}$, and the number of moles of the remaining $\mathrm{H}_{2} \mathrm{O}_{2}$. This procedure ensures the removal of the residual $\mathrm{H}_{2} \mathrm{O}_{2}$ interrupting the Fenton reactions. Before analyses, the samples were filtered through membranes with mean pore size of $0.45 \mu \mathrm{m}$.

\section{Chemical analyses}

Turbidity, $\mathrm{pH}$ and the apparent color at $465 \mathrm{~nm}$ were measured using respectively a turbidimeter $2100 \mathrm{Q}$ (Hach), a pHmeter (Bel Engineering), and a spectrophotometer (Shimadzu UV 1800), after calibration with standard solutions.

DOC was measured using a TOC analyzer (Shimadzu TOC-VCPH/CPN) equipped with an ASI-V autosampler. This parameter is obtained by subtracting the dissolved inorganic carbon (DIC) from the dissolved carbon (DC). COD determinations were carried out according to 5220D Standard Method. ${ }^{31} \mathrm{BOD}_{5}$ measurements were performed following the 5210D Standard Method, using an Oxitop IS-6 WTW and a BOD incubator (TE-371 Model TECNAL) to keep the temperature at $20{ }^{\circ} \mathrm{C} .{ }^{31}$

The $\mathrm{H}_{2} \mathrm{O}_{2}$ concentration was determined photometrically using a method proposed by Nogueira et al..$^{32}$ The concentration of total dissolved iron, after reduction with hydroxylamine, was determined directly via methodology based on the formation of a complex between $\mathrm{Fe}^{2+}$ and 1,10-phenantroline. ${ }^{31}$

The concentration of total solids (TS), suspended solids (SS), dissolved solids (DS), total nitrogen, ammoniacal nitrogen, sulfate and total phosphorus were quantified according to the respective Standard Methods. ${ }^{31}$ Chloride was quantified by the Mohr method.

A Shimadzu-2014 gas chromatograph equipped with a flame ionization detector (GC-FID) and a reverse phase Supelco SPB-5 capillary column $(30 \mathrm{~m} \times 0.25 \mathrm{~mm} \times 0.25 \mu \mathrm{m})$ was used in the qualitative evaluation of the removal of organic compounds. The temperature program settings were based in a proposition done by Rocha et al. ${ }^{33}$

The organic fraction of the landfill leachate was extracted using $\mathrm{CH}_{2} \mathrm{Cl}_{2}$ (HPLC grade) under three different $\mathrm{pH}$ values, as proposed by Zhang et al..$^{34}$

\section{Results and Discussion}

Pre-treatment by coagulation, flocculation and decantation

Aiming at reducing its intense color and the large amount of particulate material, the landfill leachate was submitted to a pre-treatment using coagulation and flocculation. This procedure is necessary since particulate materials and color tends to inhibit the access of light to the reaction medium, affecting negatively the photo-Fenton process, ${ }^{7,35}$ especially considering that the treatment proposed in this study involves the combination between these physico-chemical processes and Fenton reactions.

It is known that the control of operational parameters exerts great influence on the efficiency of a treatment using coagulation-flocculation..$^{36}$ Therefore, in this study, operational parameters such as the type $\left(\mathrm{Fe}^{3+}\right.$ or $\left.\mathrm{Al}^{3+}\right)$, salt source $\left(\mathrm{Cl}^{-}, \mathrm{NO}_{3}{ }^{-}\right.$and $\left.\mathrm{SO}_{4}{ }^{2-}\right)$ and dosage of the coagulant ion were evaluated at the natural $\mathrm{pH}$ of the raw sanitary landfill leachate ( $\mathrm{pH}$ 7.9). It is important to note that in this study the samples of this effluent were used as received, contrary to what was previously reported, ${ }^{7}$ where the $\mathrm{pH}$ was adjusted to values close to 3 during sampling, for preservation of the material. Because of this, in this case, all processes (coagulation-flocculation-decantation and photo-Fenton) occurred in this $\mathrm{pH}$. 
Figure 1 shows that the combination between the type of coagulant and its counterion influences the removal of the apparent color and turbidity.

Regarding the removal of the apparent color (Figure 1a), aluminum salts stand out, especially the chloride and nitrate ones. It is important to emphasize that $\mathrm{Fe}^{3+}$ contributes to the formation of colored compounds, and the consequent intensification of the color of the solution. ${ }^{37}$ So, a better comparison of the effectiveness of these two coagulant agents must be obtained from the analysis of the results concerning the removal of turbidity. The better results were also obtained using $\mathrm{Al}^{3+}$, especially nitrate, mainly in concentrations up close $4.4 \mathrm{mmol} \mathrm{L}^{-1}$ (Figure 1b). This results may be explained by the high amount of hydrolyzed cationic and polynuclear species of $\mathrm{Al}^{3+}$ with higher charge in $\mathrm{pH} 7.9$, when compared to $\mathrm{Fe}^{3+}$, favoring the destabilization of the suspended particles charged negatively. ${ }^{36,38}$ On the other hand, we found in a previous study $^{7}$ that a better removal by coagulation-flocculation was reached using $\mathrm{Fe}^{3+}$ instead of $\mathrm{Al}^{3+}$ when the initial $\mathrm{pH}$ was set at 3 . The role of combination between $\mathrm{pH}$ and type of coagulant was also observed during the treatment of biodiesel wastewater by coagulation-flocculation, being obtained better results at $\mathrm{pH} 9.7$ using $\mathrm{Al}^{3+}$ and at $\mathrm{pH} 5$ using $\mathrm{Fe}^{3+} .39$

In addition to the association $\mathrm{Al}^{3+} / \mathrm{NO}_{3}^{-}$, that resulted in the highest level of turbidity removal (Figure 1b), the association of this cation with $\mathrm{SO}_{4}{ }^{2-}$ and $\mathrm{Cl}^{-}$, in this order, in concentrations up close $4.4 \mathrm{mmol} \mathrm{L}^{-1}$, also influenced positively the process, although with a lower performance. This occurs because nitrate ions have a very low tendency to coordinate with metal ions. On the other hand, chloride and sulfate have moderate to strong capacity to coordinate with aluminum and iron besides being able to reduce the net charge of hydrolysis products of these metals. ${ }^{36}$ The complexation of $\mathrm{Fe}^{2+} / \mathrm{Fe}^{3+}$ by chloride and sulfate has been

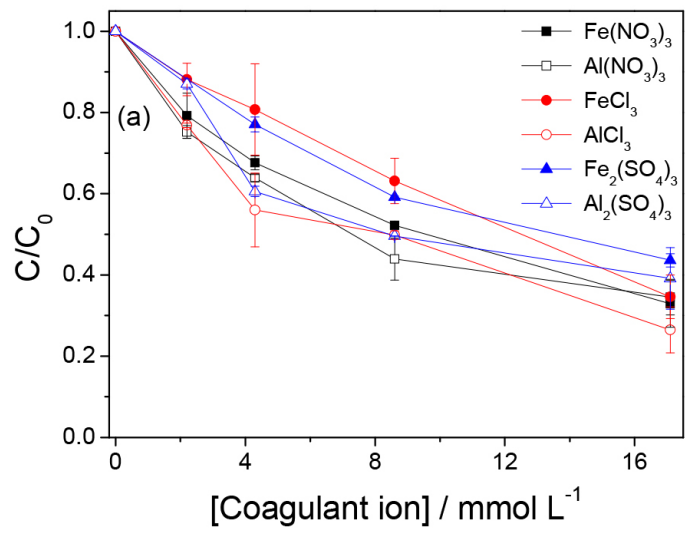

observed during degradation of the azo dye Direct Red 81 by Fenton process, causing a decrease in the efficiency of degradation when compared with experiments carried out in the absence of these inorganic anions. ${ }^{40}$ Furthermore, Silva et al. ${ }^{7}$ reported the strong influence of chloride and sulfate on the consumption of $\mathrm{H}_{2} \mathrm{O}_{2}$, extending the time required for the treatment of sanitary landfill leachate by the photo-Fenton process. Meanwhile, no influence of nitrate ions has been observed during the treatment of sanitary landfill leachate using the photo-Fenton process. ${ }^{41}$ Thus, based on our results and in the mentioned above, $\mathrm{Al}\left(\mathrm{NO}_{3}\right)_{3}$ was chosen as the best salt and used in this stage of treatment of the landfill leachate. Using $\mathrm{Al}^{3+}$ at the initial $\mathrm{pH}$ (7.9) of the landfill leachate at a concentration equal to $4.4 \mathrm{mmol} \mathrm{L}^{-1}$, a decrease of, respectively, 36 and $66 \%$ in the apparent color and turbidity was obtained (Figure 1).

Using the best experimental conditions, a total volume of $30 \mathrm{~L}$ of the effluent was treated by this process. A brief characterization of the sanitary landfill leachate, before and after coagulation-flocculation treatment is summarized in Table 1.

The natural $\mathrm{pH}$ of the raw landfill leachate was 7.9. The apparent and real color measured for this effluent was, respectively, 3135 and $1281 \mathrm{mg} \mathrm{L}^{-1}$, and a turbidity of 137 NTU (Table 1). It showed a moderate organic load (DOC $=723 \mathrm{mg} \mathrm{C} \mathrm{L}^{-1}, \mathrm{COD}=3076 \mathrm{mg} \mathrm{O}_{2} \mathrm{~L}^{-1}$ and $\mathrm{BOD}_{5}=1207 \mathrm{mg} \mathrm{O}_{2} \mathrm{~L}^{-1}$ ), although the $\mathrm{BOD}_{5} / \mathrm{COD}$ ratio of 0.39 is consistent with a non-biodegradable material. ${ }^{42}$

After the treatment by coagulation-flocculation, a partial but expressive reduction in the apparent, real color and turbidity were obtained, of respectively 36,49 and $68 \%$ (Table 1). Considering the organic fraction only in terms of DOC, since this analysis consists in the direct measurement of the organic carbon, a decrease of $19 \%$ was obtained in this stage of treatment (Table 1), a relatively significant amount considering the nature of the treatment.

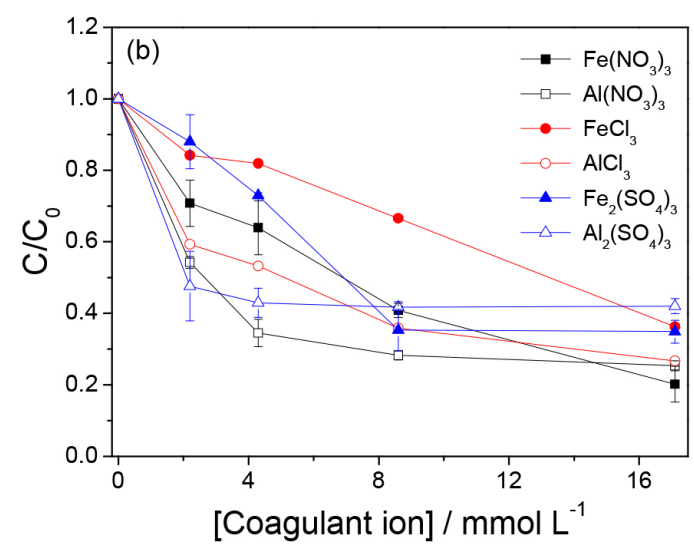

Figure 1. Influence of the dosage of coagulant ion and its counterion on the removal of (a) apparent color and (b) turbidity by coagulation-flocculation, using the combinations between $\mathrm{Fe}^{3+}$ (solid symbols) and $\mathrm{Al}^{3+}$ (open symbols) and different anions, at the initial $\mathrm{pH}$ (7.9) of the landfill leachate. 
Table 1. Characterization of the sanitary landfill leachate before and after coagulation-flocculation-decantation treatment using $4.4 \mathrm{mmol} \mathrm{L}^{-1}$ $\mathrm{Al}^{3+}$ as $\mathrm{Al}\left(\mathrm{NO}_{3}\right)_{3}$

\begin{tabular}{|c|c|c|}
\hline \multirow{2}{*}{ Parameter } & \multicolumn{2}{|c|}{ Value } \\
\hline & Before & After \\
\hline $\mathrm{pH}$ & 7.9 & 7.7 \\
\hline Apparent color / $\left(\mathrm{mg} \mathrm{L}^{-1} \mathrm{Pt} / \mathrm{Co}\right)$ & 3135 & 1988 \\
\hline Real color / (mg L'-1 Pt/Co) & 1281 & 652 \\
\hline Turbidity / NTU & 137 & 44 \\
\hline Conductivity / ( $\left.\mathrm{mS} \mathrm{cm}^{-1}\right)$ & 16.0 & 13.8 \\
\hline Alkalinity as $\mathrm{CaCO}_{3} /\left(\mathrm{mg} \mathrm{L}^{-1}\right)$ & 11640 & 5160 \\
\hline Suspended solids / $\left(\mathrm{mg} \mathrm{L}^{-1}\right)$ & 111 & 26 \\
\hline Dissolved solids / $\left(\mathrm{mg} \mathrm{L}^{-1}\right)$ & 7664 & 7125 \\
\hline Total solids / (mg L-1) & 7900 & 7643 \\
\hline $\mathrm{DC} /\left(\mathrm{mg} \mathrm{C} \mathrm{L}^{-1}\right)$ & 1266 & 996 \\
\hline $\mathrm{DIC} /\left(\mathrm{mg} \mathrm{C} \mathrm{L}^{-1}\right)$ & 543 & 413 \\
\hline $\mathrm{DOC} /\left(\mathrm{mg} \mathrm{C} \mathrm{L}^{-1}\right)$ & 723 & 583 \\
\hline $\mathrm{COD} /\left(\mathrm{mg} \mathrm{O}_{2} \mathrm{~L}^{-1}\right)$ & 3076 & 2082 \\
\hline $\mathrm{BOD}_{5} /\left(\mathrm{mg} \mathrm{O}_{2} \mathrm{~L}^{-1}\right)$ & 1207 & 490 \\
\hline $\mathrm{BOD}_{5} / \mathrm{COD}$ & 0.39 & 0.24 \\
\hline Chloride / $\left(\mathrm{mg} \mathrm{L}^{-1}\right)$ & 2425 & 2358 \\
\hline Total nitrogen / $\left(\mathrm{mg} \mathrm{L}^{-1}\right)$ & 1261 & 1220 \\
\hline Amoniacal nitrogen / $\left(\mathrm{mg} \mathrm{L}^{-1}\right)$ & 1120 & 1126 \\
\hline Sulfate / $\left(\mathrm{mg} \mathrm{L}^{-1}\right)$ & $<10$ & n.d. \\
\hline Total phosphorus / $\left(\mathrm{mg} \mathrm{L}^{-1}\right)$ & 10.6 & 2.24 \\
\hline
\end{tabular}

DC: dissolved carbon; DIC: dissolved inorganic carbon; DOC: dissolved organic carbon; $\mathrm{COD}$ : chemical oxygen demand; $\mathrm{BOD}_{5}$ : biochemical oxygen demand; n.d.: not determined.

With respect to the fraction of inorganic carbon, it was observed a decrease from 543 to $413 \mathrm{mg} \mathrm{C} \mathrm{L}^{-1}$, or about $24 \%$ (Table 1), in the content of DIC (carbonate and bicarbonate). This result agree with the changes observed in the alkalinity (the sum of the concentrations of carbonate, bicarbonate and hydroxide ions), Table 1 . The elimination of carbonate and bicarbonate ions occurred due the hydrolysis reactions mediated by $\mathrm{Al}^{3+}$, generates insoluble aluminum hydroxides and free hydrogen ions, and is confirmed by a small reduction in the $\mathrm{pH}$, from 7.9 to 7.7 (Table 1). This small decrease in the $\mathrm{pH}$ is a consequence of the high buffering capacity of the sanitary landfill leachate. ${ }^{13}$ The partial removal of these ions is advantageous for the next stage of treatment, since carbonate and bicarbonate tend to suppress the hydroxyl radicals, ${ }^{43}$ compromising the Fenton reactions. Also, the pre-treated effluent still has low biodegradability, as shown by the $\mathrm{BOD}_{5} / \mathrm{COD}$ ratio (Table 1). Thus, the integration to an additional treatment such as the photo-Fenton process is needed to ensure the minimization of the parameters pointed in Table 1 .
Treatment using the photo-Fenton process under solar irradiation

Figure 2 shows the profiles of landfill leachate mineralization applying the photo-Fenton process to the effluent treated in the previous stage. It should be emphasized that this treatment was performed without any $\mathrm{pH}$ correction (at $\mathrm{pH} 7.7$, see Table 1), using two different $\mathrm{Fe}^{3+}$ complexes $\left(2 \mathrm{mmol} \mathrm{L}^{-1}\right.$ of $\mathrm{FeCit}$ or $\left.\mathrm{FeOx}\right)$.

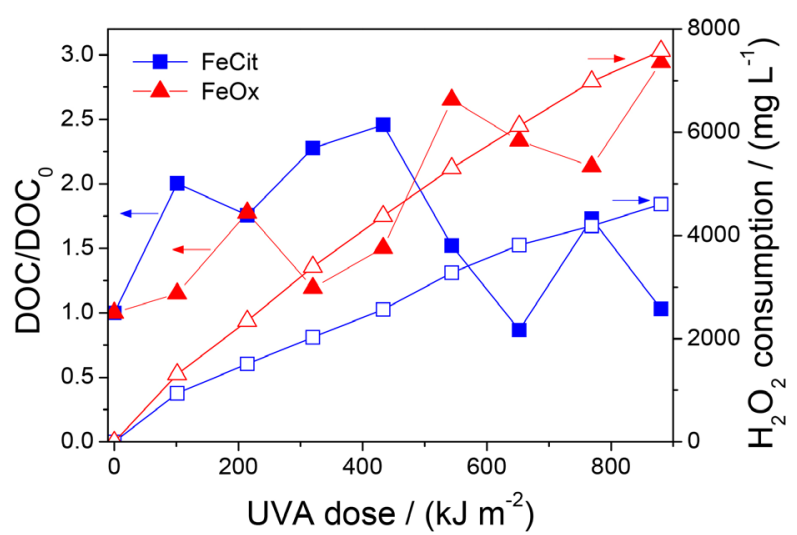

Figure 2. Influence of the iron source on mineralization (solid symbols) and $\mathrm{H}_{2} \mathrm{O}_{2}$ consumption (open symbols) during the treatment of the pretreated landfill leachate at $\mathrm{pH} 7.7$ (natural $\mathrm{pH}$ of the effluent) using the photo-Fenton process. Initial conditions: $[\mathrm{FeCit}$ or $\mathrm{FeOx}]=2 \mathrm{mmol} \mathrm{L}^{-1}$; $\left[\mathrm{H}_{2} \mathrm{O}_{2}\right]$ was maintained between $200-500 \mathrm{mg} \mathrm{L}^{-1}$ by sequential additions of $\mathrm{H}_{2} \mathrm{O}_{2}$ during the experiments.

The analysis of Figure 2 shows an oscillation of the DOC values as the accumulated UVA dose increases, showing that the dissolution of the residual suspended solids is interfering in the mineralization, suggesting the need to filter the pretreated effluent before the photocatalytic stage.

Despite this, the results shown in Figure 2 indicate that $\mathrm{FeCit}$ is, in this case, the most efficient photocatalyst, although the $\mathrm{FeOx}$ absorbs more radiation in the UVA and at wavelengths greater than $400 \mathrm{~nm}$ at pH 7.7 (Figure S1). One of the reasons for the poor performance presented by $\mathrm{FeOx}$ is that its photocatalytic activity decreases for $\mathrm{pHs}$ higher than $5 .{ }^{44-46}$ Despite the low performance of this catalyst, a high consumption of $\mathrm{H}_{2} \mathrm{O}_{2}$ was observed during the reaction, related to the quenching of hydroxyl radicals caused by carbonate/bicarbonate ions (the inorganic carbon measured in this effluent at $\mathrm{pH} 7.7$ before the photocatalytic treatment was $413 \mathrm{mg} \mathrm{C} \mathrm{L}^{-1}$ ), which must also have caused negative impact on the process mediated by FeCit, equations 1 and 2.

$\mathrm{HO}^{\bullet}+\mathrm{CO}_{3}{ }^{2-} \rightarrow \mathrm{HO}^{-}+\mathrm{CO}_{3}^{-\bullet}$
$\mathrm{HO}^{\bullet}+\mathrm{HCO}_{3}^{-} \rightarrow \mathrm{H}_{2} \mathrm{O}+\mathrm{CO}_{3}^{-} \cdot$ 
In order to assess the negative impact of the carbonate/ bicarbonate ions on the mineralization, experiments were performed at $\mathrm{pH} 5$, since it was found a decrease in the concentration of inorganic carbon from 413 to $5 \mathrm{mg} \mathrm{C} \mathrm{L}^{-1}$ with the adjustment of the $\mathrm{pH}$ of the effluent for 5 . The acidification was performed using $\mathrm{HNO}_{3}$ to avoid the introduction of anions such as sulfate or chloride, which contributes to an increase in the consumption of $\mathrm{H}_{2} \mathrm{O}_{2}$, lengthening treatment time. ${ }^{7}$

Figure 3 shows that the landfill leachate mineralization profiles changed when the initial $\mathrm{pH}$ of the effluent was adjusted to 5. Under this condition FeOx showed to be a much better photocatalyst than FeCit, which is related to the presence at this $\mathrm{pH}$ of more photoactive iron species in solution, such as $\mathrm{Fe}\left(\mathrm{C}_{2} \mathrm{O}_{4}\right)_{3}{ }^{3-}$ and $\mathrm{Fe}\left(\mathrm{C}_{2} \mathrm{O}_{4}\right)^{2-}$, 47 that speeds up the production of hydroxyl radicals, increasing the mineralization efficiency and the consumption of $\mathrm{H}_{2} \mathrm{O}_{2}$.

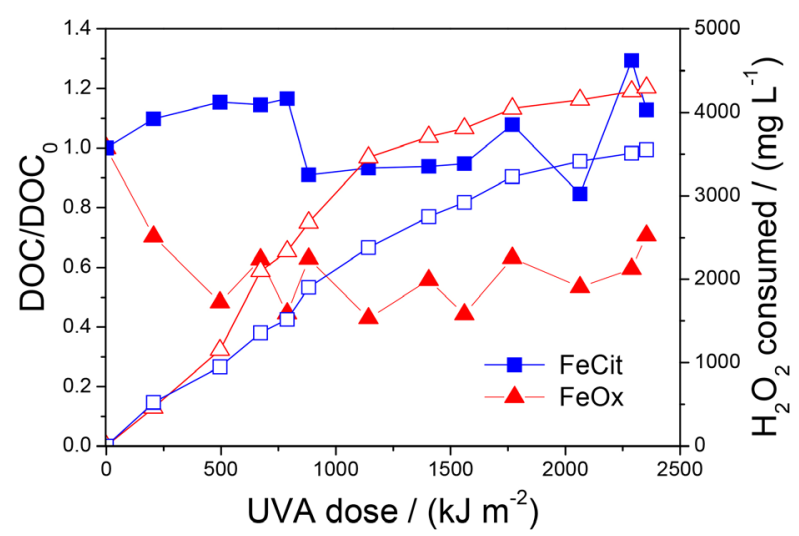

Figure 3. Influence of the iron source on the mineralization (solid symbols) of the organic load and $\mathrm{H}_{2} \mathrm{O}_{2}$ consumption (open symbols), during the treatment of the pre-treated landfill leachate using photo-Fenton process at pH 5.0. Initial conditions: $[\mathrm{FeCit}]=[\mathrm{FeOx}]=2 \mathrm{mmol} \mathrm{L}^{-1} ;\left[\mathrm{H}_{2} \mathrm{O}_{2}\right]$ was maintained between 200-500 mg L-1 by sequential additions of $\mathrm{H}_{2} \mathrm{O}_{2}$ during the experiments.

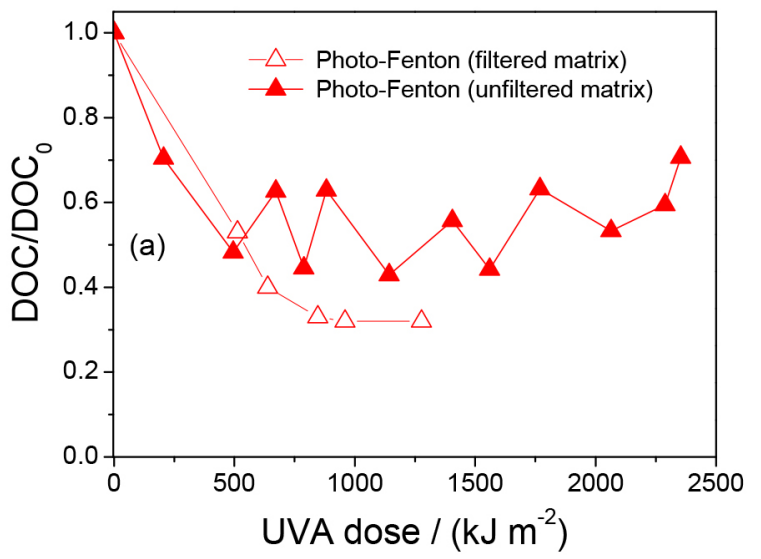

Although FeCit has been discarded as a photocatalyst for the removal of the organic load of this kind of effluent, these results demonstrate the need of reducing the $\mathrm{pH}$ of the reaction medium to a value capable of guaranteeing the removal of carbonate/bicarbonate ions, without compromising the treatment via photo-Fenton process.

Based on these results and aiming at enhancing the mineralization efficiency, in addition to promoting the adjustment of the $\mathrm{pH}$ before the treatment using photoFenton reactions, the effluent was filtered using membranes with mean pore size of $0.45 \mu \mathrm{m}$. With this, the oscillations in the DOC content, observed in Figures 2 and 3 due to the dissolution of organic matter still in suspension, during the Fenton reactions, no longer occurred (Figure 4). After filtration, the DOC of the effluent was reduced to $313 \mathrm{mg} \mathrm{L}^{-1}$.

As shown in Figure 4, after the filtration there was an enhancement of $20 \%$ in the mineralization, reaching $68 \%$ of DOC removal in the photocatalytic process. On the other hand, there was no increase in the degree of mineralization when the accumulated dose of UVA increased to $1277 \mathrm{~kJ} \mathrm{~m}^{-2}$ (Figure 4a). It is probable that this stabilization occurs due to the formation of carboxylic acids of low molar mass, recalcitrant to oxidation, ${ }^{48}$ and that also can form complexes with iron, reducing its concentration (Figure 4b). ${ }^{49}$ Additionally the precipitation of iron ions is possible to occur since the oxalate ions tend to undergo degradation simultaneously with the organic load, and the resulting iron ions can undergo hydrolysis due to the high $\mathrm{pH}$ of the medium, forming insoluble species. ${ }^{10}$

While Figure 5a provides a vision of the distribution of the organic compounds after the stage of coagulationflocculation, before the stage of $\mathrm{pH}$ adjustment and membrane filtration, Figure $5 \mathrm{~b}$ suggests an expressive removal of these compounds along with an increase in

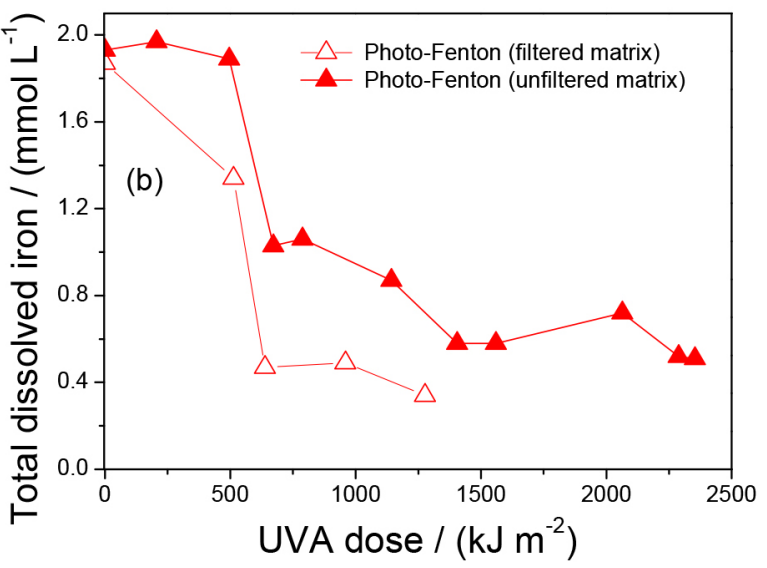

Figure 4. Profile of (a) mineralization and (b) total dissolved iron during the photo-Fenton treatment at pH 5 of the pre-treated landfill leachate, with and without filtration through membranes with pore size of $0.45 \mu \mathrm{m}$. Initial conditions: [FeOx] $=2 \mathrm{mmol} \mathrm{L}^{-1}$; $\left[\mathrm{H}_{2} \mathrm{O}_{2}\right]$ maintained between 200 and $500 \mathrm{mg} \mathrm{L}-1$ by sequential additions of $\mathrm{H}_{2} \mathrm{O}_{2}$ during the experiments. 

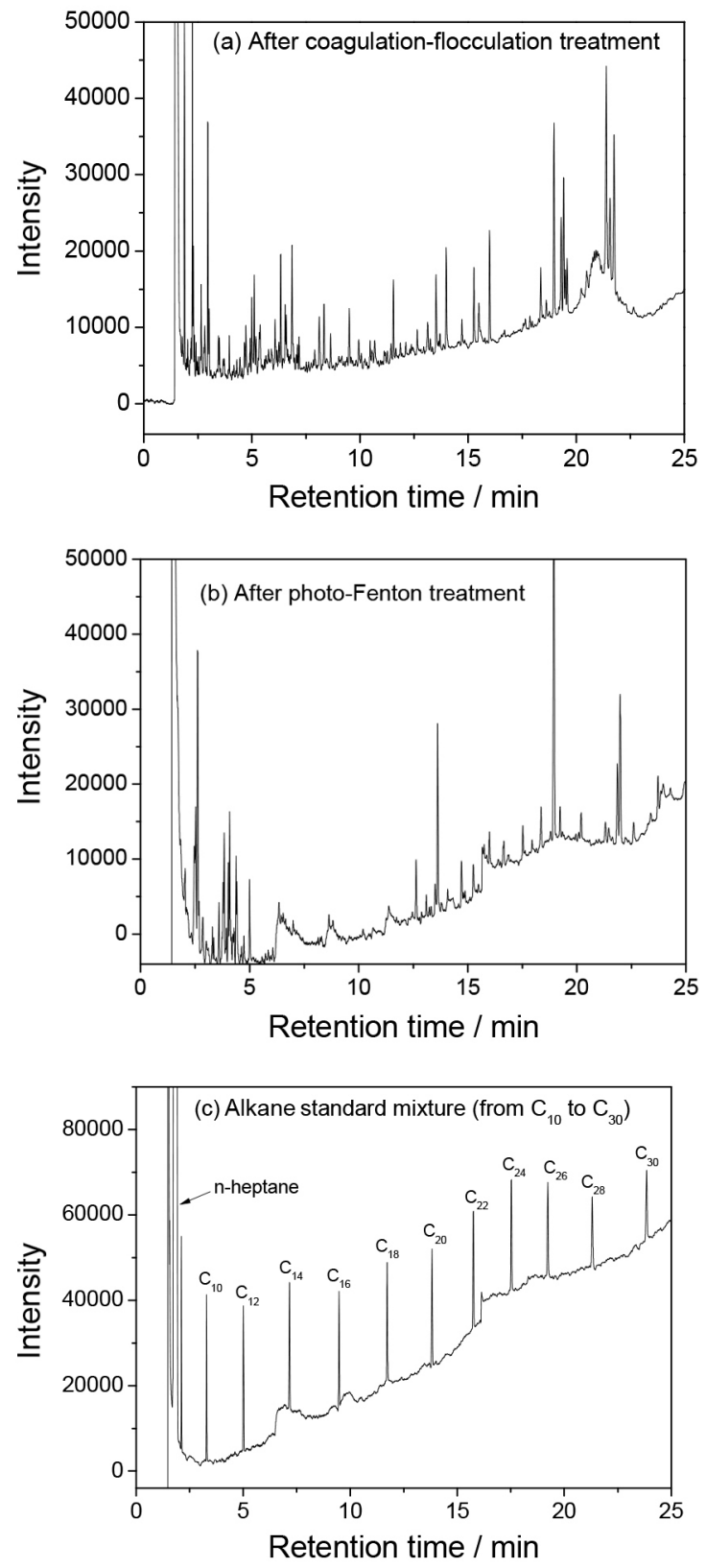

Figure 5. Data from GC-FID analysis of the (a) landfill leachate after coagulation-flocculation; (b) effluent after photo-Fenton treatment; (c) alkane standard mixture from $\mathrm{C}_{10}$ to $\mathrm{C}_{30}$. The GC-FID of the raw effluent was not possible to be done due the large amount of particulate material in its composition.

the content of low molecular weight organic fragments, after the photo-Fenton process induced by solar radiation, a behavior coherent with the results of DOC removal (Figure 4a).

Based on the results obtained in Figures $4 \mathrm{a}$ and 5, the mineralization during the treatment using photo-Fenton reactions should occur due to the conversion of complex organic structures (Figure 5a) into small organic compound (Figure $5 b$ ). This is evidenced in the comparison of the chromatograms shown in Figures $5 \mathrm{a}$ and $5 \mathrm{~b}$ with the one of
Figure 5c, once the increase in the carbonic chain is directly proportional to the retention time. A detailed characterization was done, aiming at detecting and identifying by GC-MS the organic compounds present in a sample of the sanitary landfill leachate. ${ }^{33}$ These authors identified more than 40 organic compounds including benzene, trichlorophenol, phthalic acid, phthalate esters, and high-molecular weight carboxylic acids, some of them certainly responsible for the low biodegradability of this kind of effluent, and verified that after application of the classic photo-Fenton process, it was possible to eliminate, almost totally, $65 \%$ of these compounds. Using a combination of electrochemical and Fenton reactions, Zhang et al. ${ }^{34}$ observed the complete degradation of 68 of the 87 organic pollutants previously detected and identified by GC-MS in a similar effluent. In addition, Rocha et al. ${ }^{33}$ verified, using the Zahn-Wellens test, an increase of $60 \%$ in the biodegradability after degradation of the compounds identified, fact also reported by Morais and Zamora. ${ }^{50}$ Thus, a similar behavior is expected to the effluent under study, especially considering that a residual DOC value of $100 \mathrm{mg} \mathrm{C} \mathrm{L}^{-1}$ obtained at the end of the treatment protocol proposed in this study. In this way, the overall reduction achieved in the content of the organic load was of $86 \%$. From this point, the residual DOC content most likely can be removed by an additional step involving a biological process, as proposed, for example, by Rocha et al. ${ }^{33}$

Regarding the effluent filtration step, there are numerous alternatives, which can be used on a large scale in the removal of the flocculate before the stage involving Fenton reactions. A simple and low-cost solution can be the use of sand filters, so that almost all suspended solids, after flocculation, can be removed, especially when dealing with large volumes of wastewater.

\section{Conclusions}

This study describes a protocol for treating sanitary landfill leachate that involves the integration of physico-chemical processes (coagulation-flocculation-decantation, followed by $\mathrm{pH}$ adjustment to 5 and filtration), and the use of photoFenton reactions, using solar radiation. In the coagulationflocculation treatment, performed at the natural $\mathrm{pH}$ (7.9) of the effluent, it was verified that the coagulant ion and the salt source influences in the removal of turbidity and color, being $\mathrm{Al}\left(\mathrm{NO}_{3}\right)_{3}$ the most appropriate coagulant agent. The $\mathrm{pH}$ adjustment from 7.7 to 5 , after the coagulation-flocculationdecantation process, improves the mineralization efficiency, due to the removal of inorganic ions such as carbonate and bicarbonate, detrimental for the photo-Fenton process. It is important to note that at $\mathrm{pH} 5$ more photoactive iron species should be generated. The integration of a membrane filtration 
stage, eliminated unwanted oscillations in the DOC content, which occurred during the photo-Fenton treatment using potassium ferrioxalate, reducing both the time required for the treatment, as well as the consumption of additives. It is important to emphasize that the DOC content at the end of all stages of treatment, was reduced from 723 to $100 \mathrm{mg} \mathrm{L}^{-1}$, that is, the overall reduction achieved in the content of organic load, using the proposed protocol was of $86 \%$.

\section{Supplementary Information}

Supplementary information is available free of charge at http://jbcs.sbq.org.br as PDF file.

\section{Acknowledgments}

The authors thank FAPEMIG (CEX-APQ-01388-13 and CEX-APQ-00583-13), CNPq (Project No. 470199/2013-0 and the Research Fellowships 302868/2015-1 and $307443 / 2015-9)$. This work is a collaboration research project of members of "Rede Mineira de Química" (RQ-MG), supported by FAPEMIG (Projects CEX-RED-00010-14 and RQ/MG 21762).

\section{References}

1. Tchobanoglous, G.; Theisen, H.; Vigil, S.; Integrated Solid Waste Management Engineering Principles and Management Issues; McGraw Hill: Boston, USA, 1993.

2. Renou, S.; Givaudan, J. G.; Poulain, S.; Dirassouyan, F.; Moulin, P.; J. Hazard. Mater. 2009, 150, 468.

3. Alkassasbeh, J. Y. M.; Heng, L. Y.; Surif, S.; Am. J. Environ. Sci. 2009, 5, 209.

4. Pivato, A.; Gaspari, L.; Waste Manage. 2006, 26, 1148.

5. Ribe, V.; Nehrenheim, E.; Odlare, M.; Gustavsson, L.; Berglind, R.; Forsberg, A.; Waste Manage. 2012, 32, 1886.

6. Costa Filho, B. M.; da Silva, V. M.; Silva, J. O.; Machado, A. E. H.; Trovó, A. G.; J. Environ. Manage. 2016, 174, 71.

7. Silva, J. O.; Silva, V. M.; Cardoso, V. L.; Machado, A. E. H.; Trovó, A. G.; J. Braz. Chem. Soc. 2016, 27, 2264.

8. Miralles-Cuevas, S.; Oller, I.; Agüera, A.; Ponce-Robles, L.; Sánches-Perez, J. A.; Malato, S.; Catal. Today 2015, 252, 78.

9. Pignatello, J. J.; Environ. Sci. Technol. 1992, 26, 944.

10. Pignatello, J. J.; Oliveros, E.; MacKay, A.; Crit. Rev. Environ. Sci. Technol. 2006, 36, 1.

11. Nogueira, R. F. P.; Guimarães, J. R.; Water Res. 2000, 34, 895.

12. Carra, I.; Casas López, J. L.; Santos-Juanes, L.; Malato, S.; Sánches Pérez, J. A.; Chem. Eng. J. 2013, 224, 67.

13. Vilar, V. J. P.; Silva, T. F. C. V.; Santos, M. A. N.; Fonseca, A.; Saraiva, I.; Boaventura, R. A. R.; Sol. Energy 2012, 86, 3301.
14. Papoutsakis, S.; Miralles-Cuevas, S.; Oller, I.; Garcia Sanchez, J. L.; Pulgarin, C.; Catal. Today 2015, 252, 61.

15. Ruales-Lonfat, C.; Barona, J. F.; Sienkiewicz, A.; Vélez, J.; Benítez, L. N.; Pulgarín, C.; Appl. Catal., B 2016, 180, 379.

16. Souza, B. M.; Dezotti, M. W. C.; Boaventura, R. A. R.; Vilar, V. J. P.; Chem. Eng. J. 2014, 256, 448.

17. Souza, D. R.; Trovó, A. G.; Antoniosi Filho, N. R.; Silva, M. A. A.; Machado, A. E. H.; J. Braz. Chem. Soc. 2013, 24, 1451.

18. Silva, M. R. A.; Vilegas, W.; Zanoni, M. V. B.; Nogueira, R. F. P.; Water Res. 2010, 44, 3745.

19. Nogueira, R. F. P.; Silva, M. R. A.; Trovó, A. G.; Sol. Energy 2005, 79, 384.

20. Machado, A. E. H.; Xavier, T. P.; de Souza, D. R.; de Miranda, J. A.; Duarte, E. T. F. M.; Ruggiero, R.; de Oliveira, L.; Sattler, C.; Sol. Energy 2004, 77, 583.

21. Manenti, D. R.; Soares, P. A.; Módenes, A. N.; EspinozaQuiñones, F. R.; Boaventura, R. A. R.; Bergamasco R.; Vilar, V. J. P.; Chem. Eng. J. 2015, 266, 203.

22. Conte, L. O.; Schenone, A. V.; Alfano, O. M.; J. Environ. Manage. 2016, 170, 60.

23. Rocha, J. C.; Rosa, A. H.; Cardoso, A. A.; Introdução à Química Ambiental, 2a ed.; Bookman: Porto Alegre, Brasil, 2009.

24. Uyguner-Demirel, C. S.; Bekbolet, M.; Chemosphere 2011, 84, 1009.

25. Vilar, J. P. V.; Rocha, E. M. R.; Mota, F. S.; Fonseca, A.; Saraiva, I.; Boaventura, R. A. R.; Water Res. 2011, 45, 2647.

26. Wang, X.; Chen, S.; Gu, X.; Wang, K.; Waste Manage. 2009 , 29, 1354.

27. Hatchard, C. G.; Parker, C. A.; Proc. R. Soc. London 1956, 235 , 518.

28. Nogueira, R. F.; Trovó, A. G.; Paterlini, W. C.; Water Sci. Technol. 2004, 49, 195.

29. Sattler, C.; de Oliveira, L.; Tzschirner, M.; Machado, A. E. H.; Energy 2004, 29, 835.

30. Soares, P. A.; Batalha, M.; Souza, S. M. A. G. U.; Boaventura, R. A. R.; J. Environ. Manage. 2015, 152, 120.

31. Clesceri, L. S.; Greenberg, A. E.; Eaton, A. D.; Standard Methods for Examination of Water \& Wastewater, $21^{\text {st }}$ ed.; American Public Health Association (APHA), American Water Works Association (AWWA) \& Water Environment Federation (WEF): Washington, USA, 2005.

32. Nogueira, R. F. P.; Oliveira, M. C.; Paterlini, W. C.; Talanta 2005, 66, 86 .

33. Rocha, E. M. R.; Mota, F. S.; Vilar, V. J. P.; Boaventura, R. A. R.; Environ. Sci. Pollut. Res. 2013, 20, 5994.

34. Zhang, H.; Wu, X.; Li, X.; Chem. Eng. J. 2012, $210,188$.

35. Trovó, A. G.; Hassan, A. K.; Sillanpää, M.; Tang, W. Z.; Int. J. Environ. Sci. Technol. 2016, 13, 147.

36. Duan, J.; Gregory, J.; Adv. Colloid Interface Sci. 2003, 100-102, 475. 
37. Teh, C. Y.; Budiman, P. M.; Shak, K. P. Y.; Wu, T. Y.; Ind. Eng. Chem. Res. 2016, 55, 4363.

38. Libânio, M.; Fundamentos de Qualidade e Tratamento de Água, $3^{\mathrm{a}}$ ed.; Editora Átomo: Campinas, Brasil, 2010.

39. Gonçalves, B. R.; Borges Neto, W.; Machado, A. E. H.; Trovó, A. G.; J. Braz. Chem. Soc., in press DOI: 10.21577/01035053.20160231.

40. Marson, E. O.; de Paiva, V. A. B.; Gonçalves, B. R.; Gomes Júnior, O.; Borges Neto, O.; Machado, A. E. H.; Trovó, A. G.; Environ. Sci. Pollut. Res., in press DOI: 10.1007/s11356-0166977-6.

41. Deng, Y.; Rosario-Muniz, E.; Ma, X. M.; Waste Manage. Res. 2012, 30, 12.

42. Marco, A.; Esplugas, S.; Saum, G.; Water Sci. Technol. 1997, $35,321$.

43. Trovó, A. G.; Nogueira, R. F. P.; J. Braz. Chem. Soc. 2011, 22, 1033.
44. Malato, S.; Fernández-Ibáñez, P.; Maldonado, M. I.; Blanco, J.; Gernjak, W.; Catal. Today 2009, 147, 1.

45. Safarzadeh-Amiri, A.; Bolton, J. R.; Carter, S. R.; Water Res. 1997, 31, 787.

46. Balmer, M. E.; Sulzberger, B.; Environ. Sci. Technol. 1999, 33, 2418.

47. Doumic, L. I.; Soares, P. A.; Ayude, M. A.; Cassanello, M.; Boaventura, R. A. R.; Vilar, V. J. P.; Chem. Eng. J. 2015, 277, 86.

48. Trovó, A. G.; Nogueira, R. F. P.; Agüera, A.; Fernandez-Alba, A. R.; Malato, S.; Water Res. 2012, 46, 5374.

49. Baba, Y.; Yatagai, T.; Harada, T.; Kawase, Y.; Chem. Eng. J. 2015, 277, 229.

50. Morais, J. L.; Zamora, P. P.; J. Hazard. Mater. 2005, 123, 181.

Submitted: November 26, 2016

Published online: January 24, 2017 